\title{
Significados das práticas religiosas para a saúde de imigrantes haitianos em Cuiabá-MT
}

\author{
Dilvania Costa Coutinho* \\ Luís Henrique da Costa Leão** \\ Leonardo Gonçalves de Alvarenga***
}

\section{Resumo}

Esse artigo aborda a relação entre práticas religiosas, imigração e saúde entre haitianos em Cuiabá, capital do estado do Mato Grosso. Considerando a relevância da religião para a saúde e a ausência de publicações sobre haitianos na capital mato-grossense, essa pesquisa teve como objetivo analisar as práticas religiosas e seus sentidos entre esses imigrantes em seu cotidiano de integração à sociedade. Foi realizada uma pesquisa qualitativa com inspiração etnográfica. O trabalho de campo durou doze meses e foram realizadas conversas informais e entrevistas com líderes religiosos haitianos e frequentadores das igrejas além de observação participante e registros nos diários de campo. Foram abordadas duas igrejas protestantes formadas pelos imigrantes. Buscou-se uma aproximação à religiosidade da população haitiana imigrante, seus saberes e práticas, costumes e sofrimentos. Essa pesquisa mostrou que na dinâmica de inserção de imigrantes haitianos na sociedade brasileira a religião tem se destacado como apoio social relevante contribuindo para a saúde e para a manutenção de uma identidade transnacional. Também percebeu-se a existência de fronteiras entre o dizível e o indizível que separa uma memória coletiva subterrânea da sociedade civil dominada ou de grupos específicos.

Palavras-chave: Religião, imigração, apoio social, saúde, protestantismo

* Universidade Federal de Mato Grosso. Mestre em Saúde Coletiva. dil.coutinho@hotmail.com .

** Universidade Federal de Mato Grosso. Doutor em Ciências na área de Saúde Pública pela Escola Nacional de Saúde Pública (ENSP/Fiocruz). Pós-doutor na Universidade de Padova, Itália e Universidade de Nottingham, Inglaterra. Professor Adjunto IV da Universidade Federal de Mato Grosso, Departamento de Saúde Coletiva (DSC/UFMT), Programa de Pós-Graduação em Saúde Coletiva e Programa de Pós-Graduação em Psicologia. luisleaoufmt@gmail.com .

*** Universidade Estadual Norte Fluminense. Doutor em Ciência da Religião (PUC-SP). Pósdoutor em Sociologia Política (UENF-RJ). Pós-doutor em Políticas Sociais (UENF-RJ), alvarengalg@hotmail.com . 


\title{
Meanings of Religious Practices to Haitian Immigrants'S Health in Cuiabá-MT.
}

\begin{abstract}
The paper addresses religious practices, immigration and health among Haitian immigrants in Cuiabá, State of Mato Grosso (MT). Regarding the importance of religion to health status and the lack of publications on Haitians in Mato Grosso, this research aimed to analyze religious practices and it's meanings among these immigrants in their daily integration into society. It was done a qualitative research from an ethnography perspective. The fieldwork lasted twelve months and informal conversations and interviews were conducted with Haitian religious leaders and churchgoers in addition to participant observation and field diary records. Two Protestant churches formed by immigrants were approached. It was sought better understandings on Haitian immigrant population's religiosity, their knowledge and practices, customs and sufferings. This research showed draw that, in the dynamics of Haitian immigrant's integration in Brazilian society, the religion has been highlighted as a relevant social support, promoting health and keeping a transnational identity. The results showed, as well, the existence of boundaries between what people say and what is unspeakable related to underground collective memory from the dominated civil society or from specific groups.
\end{abstract}

Keywords: Religion, immigration, social support, health, Protestantism

\section{Significados de las prácticas religiosas para la salud de los inmigrantes haitianos en Cuiabá-MT}

\section{Resumen}

Este artículo aborda la relación entre prácticas religiosas, inmigración y salud entre los haitianos en Cuiabá, capital del estado de Mato Grosso. Considerando la relevancia de la religión para la salud y la ausencia de publicaciones sobre los haitianos en la capital de Mato Grosso, esta investigación tuvo como objetivo analizar las prácticas religiosas y sus significados entre estos inmigrantes en su integración diaria a la sociedad. Se realizó una investigación cualitativa con inspiración etnográfica. El trabajo de campo duró doce meses y se llevaron a cabo conversaciones y entrevistas informales con líderes religiosos haitianos y asistentes a la iglesia, así como observación participante y registros del diario de campo. Se acercó a dos iglesias protestantes formadas por inmigrantes. Se buscó una aproximación a la religiosidad de la población inmigrante haitiana, sus conocimientos y prácticas, costumbres y sufrimientos. Esta investigación mostró que en la dinámica de inserción de los inmigrantes haitianos en la sociedad brasileña, la religión se ha destacado como un soporte social relevante, contribuyendo a la salud y al mantenimiento de una identidad transnacional. También se advirtió la existencia de fronteras entre lo decible y lo indecible que separan una memoria colectiva clandestina de la sociedad civil dominada o de grupos específicos.

Palabras clave: religión; inmigración; apoyo social; salud; protestantismo. 


\section{Introdução}

Atualmente existem cerca de 3000 haitianos vivendo na região de Cuiabá-Mato Grosso. Desde o ano de 2012, Cuiabá-MT tornou-se destino desses imigrantes devido às oportunidades de emprego nas obras da Copa do Mundo de 2014. Em geral, eles têm frágil inserção social, ocupam postos de trabalho de maior risco à saúde com baixos salários, moradias precárias e dívidas do processo migratório (Leão et al 2017).

Essa nova dinâmica populacional e situação social gerou a necessidade de melhor compreensão sobre os aspectos centrais para o cuidado em saúde com esse grupo populacional. Logo observou-se um forte discurso e prática religiosa entre eles e uma história particularmente chamou a atenção: um haitiano adoeceu e, mesmo depois de muitos gastos financeiros para chegar ao Brasil, retornou ao seu país para buscar tratamento para seu problema de saúde. Ele adoecera assim que chegara ao Brasil e, por um ano, buscou tratamento nos serviços de saúde em MT, mas sem êxito no diagnóstico. Diante da falta de respostas do sistema de saúde brasileiro, ele retornou ao seu país para tratar-se com seu líder religioso. Ele era praticante do vodu, uma das práticas religiosas mais marcantes do Haiti. Esse caso demonstrou a necessidade de maior aproximação à cultura haitiana, suas práticas de saúde autônomas, seus entendimentos e experiências particulares do processo saúde-doença-cuidado e o papel da religião nesse âmbito.

Isso foi reforçado pelo fato de que justamente as instituições de inspiração religiosa - como o Centro Pastoral para Migrantes (CPM) e as igrejas cristãs ofereceram o apoio para integração dessa população à sociedade e foram constantemente acessadas por haitianos.

Por outro lado, o papel da religião nas análises dos processos saúdedoença das populações nem sempre é considerado devidamente e profissionais de saúde, em geral, não são preparados para compreender e lidar com essa dimensão da cultura no cuidado em saúde. Isso porque, discursos no cenário social brasileiro, principalmente nas mídias, revelam leituras generalizadas e uniformizadoras da religiosidade haitiana alimentando preconceitos e discriminações que demonizam e inferiorizam esse grupo.

Diversos estudos apontam o significativo papel da religião na saúde de imigrantes em virtude das situações de instabilidade social e vulnerabilidade a agravos decorrentes do processo migratório (Joseph 2014; Padilla 2013; Pussetti 2009; Trad 2003). Desenraizamento social, diferenças culturais, falta de domínio da língua oficial, mudança na condição econômica e no status 
social, discriminação racial e intolerância étnica podem mediar processos de adoecimento nessa população (Silva, 2008). Estudos verificaram que experiências religiosas de imigrantes podem atuar como recursos simbólicos de proteção, oferta de sentido frente aos sofrimentos da jornada migratória e resgate da dignidade (Marinucci 2013; Pereira 2016). Outras publicações reafirmam a importância do envolvimento comunitário frente ao sofrimento de imigrantes destacando o estímulo à participação comunitária de grupos recém-chegados como modo de integração social (Bartel 2016; Da Silva 2013), reforço à autoestima e ajuda humanitária (Franken et al 2012; Freitas 2013), auxílio à reconstrução da identidade e à vontade de viver diante de adversidades (Carrasco 2015; Da Silva 2015; Evangelista 2010); fortalecimento da participação em associações e cooperação com órgãos públicos em prol da cidadania (De Sá 2015; Santos 2016). Assim, considerando o lugar da cultura e da religião no processo saúde-doença de imigrantes, esse tem o objetivo de analisar as práticas religiosas e seus sentidos entre esses imigrantes haitianos.

\section{Trajetória metodológica}

\subsection{Tipo da pesquisa e participantes}

Foi realizada uma pesquisa qualitativa com inspiração etnográfica. A etnografia (ethos - cultura e graphe - escrita) provém da Antropologia Cultural, entendida como "uma maneira de estudar pessoas em grupos organizados, duradouros, que podem ser chamados de comunidades ou sociedades" (Angrosino 2009, p. 16). Dá-se ênfase ao modo peculiar de vida, cultura, comportamentos, costumes e crenças aprendidas e compartilhados, como um mergulho para observar e interpretar modos de vida (Geertz 1989; Malinowsky 1978). Essa pesquisa, descritiva-reflexiva, buscou articular dados empíricos das instituições religiosas e da religiosidade de haitianos colocandoas em diálogo. Buscou-se uma aproximação à religiosidade da população haitiana imigrante, seus saberes e práticas, costumes e sofrimentos. Foi inspirada também pela proposta de George E. Marcus sobre uma etnografia das migrações ou multilocal (Marcus 1995) por permitir explorar situações em espaços sociais diferentes acompanhando a diversidade de experiências vividas em mobilidade.

A imersão no campo durou doze meses e possibilitou o conhecimento das instituições religiosas, o acesso e a permanência em locais de culto, a aceitação do grupo, interação em momentos ritualísticos e festivos (batismo, 
casamento e funerais) e no cotidiano como em visitas nas residências.

Participaram deste estudo, adultos, tanto homens como mulheres nativos do Haiti, que residiam na capital mato-grossense, frequentavam uma instituição religiosa adstrita ao campo de pesquisa ou tinham alguma experiência religiosa. Escolhemos incluir os locais de reuniões com presença expressiva de imigrantes haitianos. Buscou-se um lugar que congregasse o maior número de imigrantes e, a partir daí averiguarmos qual o melhor cenário para analisar as práticas religiosas. Não houve escolha prévia sobre a tradição religiosa a ser investigada. $\mathrm{Na}$ aproximação com o campo da pesquisa identificou-se grande número de haitianos cristãos, católicos e evangélicos e houve dificuldades para acessar praticantes do Vodu e de religiões afrodescendentes.

Assim, foram escolhidas para a análise duas igrejas protestantes. A primeira instituição é de matriz protestante presbiteriana e foi escolhida por ter sido a primeira comunidade religiosa-étnica haitiana formada em Cuiabá. A segunda selecionada foi uma comunidade batista, pelo acesso a um grande grupo de haitianos e por ser de tradição protestante histórica, similar ao grupo presbiteriano. Essas comunidades étnicas são aquelas que agrupam apenas haitianos. Uma é liderada por um missionário haitiano enviado para o Brasil pela instituição religiosa Presbiteriana do Haiti e acolhido pela instituição brasileira de mesma tradição e a outra, inserida em uma comunidade evangélica local da qual se destaca seu líder brasileiro. Tal escolha ocorreu também pelas vivências e experiências dos líderes e seus papéis na comunidade.

\subsection{Locais, procedimentos e técnicas}

O estudo se deu na regional leste da cidade de Cuiabá por ser local de grande circulação de haitianos escolhido por muitos deles (existem ali muitas inscrições em muros e portas com dizeres crioulos e francês - uma espécie de demarcação de território). O local foi escolhido ainda pela presença e proximidade de muitas instituições religiosas, incluindo o Centro Pastoral do Migrante, especialmente por abrigar o grupo religioso haitiano mais antigo segundo relatos obtidos nas aproximações com o campo: os presbiterianos.

Utilizou-se a observação participante para investigar interações nas reuniões de grupos religiosos e em instituições locais que acolhem os haitianos observando relações sociais, tradições, crenças, expressões e sentimentos. 
Foram realizadas conversas informais e entrevistas, deixando os sujeitos com liberdade para falar o quanto quisessem e sobre o que quisessem dentro do tema da religião e seu papel com algumas perguntas voltadas ao modo de vida e os sentidos das experiências religiosas. Foram desenvolvidos roteiros para nortear a coleta de dados: entrevista semiestruturada com os líderes religiosos e um roteiro para diálogo com os haitianos.

Foram feitos ainda registros nos cadernos de campo elaborados com roteiro sobre aspectos descritivos e reflexivos, embasado nas recomendações dos autores com experiência no método para a confecção do diário de campo. A pesquisa foi apreciada por comitê de ética e aprovada conforme número 29120414.0.0000.5541.

\subsection{Análise e limitações}

A pesquisa parte do pressuposto de que é improvável que a realidade seja totalmente apreendida e nossa análise buscou descrever e interpretar palavras, experiências, comportamentos e normas do grupo observado no sentido de uma "descrição densa" (Malinoswski 1978), para produzir uma compressão mais clara sobre os papeis da religião.

Depois das leituras do material fruto da observação participante, entrevistas e notas do diário de campo, seguiu-se a classificação das interpretações conforme Duarte (2002 p. 152) "cruzando informações aparentemente desconexas, interpretando respostas, notas e textos integrais que são codificados em 'caixas simbólicas', categorias teóricas ou 'nativas"'. Buscamos fazer dialogar esses conteúdos, categorizando-os e conformando eixos analíticos, confrontando-os entre si e com a literatura acadêmica relativa à religião, imigração e saúde.

A descrição da religiosidade haitiana e das ações das instituições religiosas foi feita sem a pretensão de estabelecer comparações ou mesmo fazer denúncias quanto à assistência social dedicada, mas permitir reflexões sobre a religião e seus papéis para esse grupo.

Além da complexidade do tema, uma das principais dificuldades enfrentadas na pesquisa refere-se à linguagem. O maior número de contato com a população ocorreu durante as reuniões religiosas realizadas na língua nativa. Nas situações do dia-a-dia, eles não utilizam o português uns com outros, mesmo aqueles que possuem fluência. Boas (2004) adverte sobre a necessidade do acesso à língua da cultura que se trabalha, possibilitando que o pesquisador mesmo reconheça as tradições sem precisar de intérprete. 
Apesar dessas dificuldades iniciais, a experiência de pesquisa tornouse rica, pois, muitos dos haitianos, ao se depararem com as limitações desse âmbito, se dispunham a ajudar criando disposição para viabilizar um diálogo compreensivo e satisfatório na língua portuguesa. Compreendemos que a barreira da comunicação intercultural foi vencida com o vínculo com aqueles já adaptados à língua portuguesa. Para as entrevistas, priorizou-se aqueles que eram capazes de compreender a língua portuguesa.

\section{Resultados e discussão}

\subsection{Características das comunidades religiosas étnicas}

As duas comunidades em foco foram criadas no ano de 2004, como resultado de atividades missionárias. Os espaços são pequenos e ornamentados por cores do Haiti. A frequência é alta em ambas. As duas comunidades tinham celebrações dominicais matutinas e em dias de semana. A maioria dos imigrantes ali é composta de homens jovens e de meia-idade e as mulheres com idade mais avançada. Percebeu-se características comuns em termos de vestimentas demonstrando poucas mudanças referentes a esses hábitos. Valoriza-se muito o jeito de se vestir, com cores e combinações de vários tipos. Mesmo crianças vestem-se bem. "É preciso estar bonito na Casa do Senhor, aqui todo dia é dia de festa, porque mais um dia Ele nos deu de vida" diz um dirigente da comunidade batista.

Lima e Valla (2005) afirmam que pessoas ao frequentarem igrejas evangélicas possuem além das vestimentas, seus comportamentos reconhecidos no meio da comunidade não cristã. Tais atitudes foram observadas na comunidade circunvizinha às igrejas, pois ao descreverem seus vizinhos, primeiramente identificavam os haitianos evangélicos/protestantes, descrevendo roupas comportadas e o hábito de carregarem as bíblias nas mãos enquanto relatos de embriaguez, agressividade e constantes brigas familiares se referiam mais aos não frequentadores desses espaços religiosos.

Quanto à liturgia e ritos, percebe-se que são longas reuniões aguardadas durante a semana com ansiedade por eles. Ao chegarem, com alegria, eles se cumprimentam em calorosos abraços. Nos cultos, há um misto de emoções: alegrias e tristezas, lágrimas e sorrisos. As músicas se destacam, cantadas em crioulo, acompanhadas por palmas e instrumentos. Muitos disseram que cantar as mesmas músicas da terra natal lhes proporcionava uma sensação de bem-estar e conforto. A música haitiana exerce uma função de centralidade 
na conformação da comunidade étnica (Pereira 2016). A presença de vários cantos que envolvem a temática da esperança aguça as lembranças da musicalidade vivida no Haiti e similarmente continuada no Brasil. Essa experiência cultural-religiosa "transfronteiriça" mobiliza memórias de lugares vividos que são ressignificadas para uma nova vivência. Esse comportamento se aproxima de um ritual típico de determinados grupos religiosos, conforme diz o historiador das religiões Mircea Eliade (2001) a respeito de um illud tempus, isto é, celebrações litúrgicas que remetem para um tempo evocado pelos Evangelhos ou outros textos sagrados que é um tempo histórico, que teve lugar próprio em determinada situação histórica.

Testemunhos ou oportunidades para cantarem eram frequentes, e podiase notar o entusiasmo que sentiam ao se dirigirem ao microfone para contarem suas experiências. Confirmam Lima e Valla (2005) que os ambientes nas igrejas pentecostais são entusiásticos, desde a entrada onde recepcionistas sorridentes apertam as mãos de quem chega até o clima confiante das canções, de forma que não era diferente essa sensação, todas às vezes ao adentrar nos espaços de reuniões das comunidades haitianas. Essa performance litúrgica comum às igrejas pentecostais se aplica à comunidade batista analisada, por se tratar de um ramo pentecostalizado dessa denominação histórica (Alvarenga 2017).

As preces são realizadas em alta voz na língua materna, de joelhos virados para o assento dos bancos ou cadeiras. As mulheres, principalmente, se viram para a parede e em pé levantam as mãos. Outros andam de um lado para o outro. São comuns gritos eufóricos de aclamação: "Iwanj pou Bondye!" (Glória a Deus) ou "Alèlja!" (aleluia) "Merci Seigneur” (Obrigado, Senhor). Nesse ambiente emotivo, muitos choram em suas petições ao divino.

Havia ainda o recolhimento dos dízimos e doações espontâneas e alguns haitianos se dirigiam com entusiasmo cantando, dançando e batendo palmas para depositar seu envelope nominal. Justificavam tal exaltação porque "se podiam ofertar era por estar empregados".

A exposição da bíblia era realizada por líderes das comunidades religiosas (pastores), o que é comum nas igrejas evangélicas históricas. Ao final do culto, era comum alguma mulher aproveitar a ocasião e oferecer produtos de venda ou entregar encomendas para auxiliar na renda.

Essas reuniões religiosas são narradas como relação com o divino e compartilhamentos fraternais reatualizados a cada celebração através de oração, leitura da Bíblia e músicas. O que se observou com isso é que a religião ofereceu senso de pertencimento, contribuiu para manutenção a 
identidade dos imigrantes e foi rede de apoio social diante de situações cotidianas e de crise. Ao mesmo tempo, chamou atenção o silenciamento de formas de religião mais características especialmente o Vodu.

\subsection{Pertencimento, socialização e o trabalho religioso}

Os principais motivos referidos para frequentar os encontros religiosos eram o sentimento de pertencimento, a oportunidade de sociabilizar com seus pares e de desenvolver atividades nesse espaço. Isso indica que a busca pela religião não se dá apenas para solução de problemas materiais, mas resulta igualmente da "vontade de viver a vida da forma mais plena possível" (Valla 2002, p. 67) e dotando-a de sentido e tornando-a mais significativa.

Ter com quem compartilhar problemas e contar ocorrências do dia-a-dia significava muito para os haitianos sempre relatando sentiremse confortáveis e seguros nos grupos. Para alguns, o ponto central é o sentimento de terem sido úteis ao trabalho religioso.

Seja com propósito de ocuparem o seu tempo ocioso ou conhecerem outras pessoas, eles relatam se sentirem reconhecidos ali. Passaram a atuar no grupo musical até mesmo ajudando no ensino religioso. Há aqueles que evangelizam e trazem novos frequentadores e aqueles que visitam as casas e atendem necessidades emergenciais dos menos favorecidos ou adoecidos.

Uma particularidade foi observada no que diz respeito aos líderes e dirigentes de culto. Dos entrevistados apenas o líder da presbiteriana se declarou formado oficialmente para o cargo. Mesmo não oficializados, o trabalho realizado por líderes leigos era muito valorizado. Vários dos imigrantes desejam inclusive ter função eclesiástica de pastoreio, que no caso das instituições brasileiras se exige obrigatoriamente o preparo teológico. Essa situação também aparece em Pereira (2016), mas poucos possuem condições financeiras para custear o curso teológico.

Devemos observar que, na realidade, alguns perfazem tripla jornada do serviço eclesiástico, pois, acumulam estudo, atividade religiosa e jornada de emprego durante a semana. Esse aspecto ressalta intenso esforço exigido na manutenção das atividades religiosas. Mas a chance de estar ativo no serviço eclesiástico aumenta o compromisso com a comunidade e dá sensação de satisfação.

Ao serem indagados porque estavam frequentando aquele lugar muitos respondiam: "Quando estou aqui sinto como se estivesse no Haiti!". A referência da comunidade religiosa como proporcionadora de sentimentos similares ao 
aconchego familiar foi a categoria mais elencada em campo. "A igreja é nossa família, são todos irmãos, família cuida um do outro", afirma o dirigente batista. "Quando eu cheguei, não tinha amigo, não conhecia ninguém. Eles me ajudaram muito".

Era bastante comum ver indivíduos transmitirem o culto ao vivo por seu celular para suas famílias. O líder dizia que a mídia alcançava quem não poderia estar presente e esse recurso é para ajudar pessoas. Entrevistados disseram ser esta a oportunidade mais fácil de sua família participar de uma celebração, pois muitos estavam em lugares onde não havia igreja próxima ou por morarem em uma zona rural, teria que viajar até a cidade.

Vários haitianos revelaram ser o espaço religioso seu único espaço de lazer. A convivência na comunidade religiosa oportunizou amizades facilitando até suas relações interpessoais na comunidade local ajudando-os a se sentirem mais seguros e aceitos.

Essas afirmações chocam-se à afirmativa de De Sá (2015 p. 120) sobre haitianas em Belo Horizonte que o fato da constante utilização dos haitianos da língua nativa entre si proporciona o fortalecimento dos laços de solidariedade dos grupos de imigrantes, mas, por outro lado dificulta as "chances de mudança gradual para a língua do país de destino".

No culto o uso da língua nativa é importante para eles sentirem tal espaço "como um pedacinho do Haiti". Apesar disso, nossa pesquisa reconhece que as redes de sociabilidades internas dos imigrantes se fortalecem, o que pode dificultar a adaptação à nova língua (até pela propensão à formação das comunidades religiosas exclusivas dos haitianos), mas observamos que os líderes orientam a exercitarem o português entre si, para aprenderem mais rápido e buscam dar oportunidades de aprendizado do idioma.

Sobre essa convivência social, diz um líder "o que atrai os fiéis é a comunhão fraternal. Aqui se sentem um pouco perto do Haiti. Vêm pra se sentir família... porque eles sofrem "com a solidão, é difícil ficar longe". Refere que refazer a vida longe de quem se ama, estar sozinho todos os dias é difícil, e, por isso, muitos procuraram o convívio com seus conterrâneos e acabaram permanecendo na igreja.

A análise das falas dos sujeitos retrata o fenômeno antropológico percebido no processo migracional descrito por Marinucci (2013) e Santos (2016), em que os indivíduos têm de dar sentido ao presente fundamentado no passado, percebido na necessidade de darem continuidade em suas vidas, tal qual estavam familiarizados no Haiti, a saber, frequentar lugares de culto e seus ritos, encontros com o sagrado ou acompanhar a família ou simplesmente para encontrar com os amigos. 
Isso remete às duas funções da religião que segundo Berger (1985) cimenta união entre agrupamentos humanos, representando um corpo de crenças com as quais estes se identificam e legitima a criação de estruturas sociais, leis, costumes e até mesmo práticas políticas, e, no âmbito individual, fornece uma explicação da vida e de seu sentido.

\subsection{A manutenção da identidade}

Outro elemento observado é a religião como fator importante para a manutenção da identidade e revitalização de experiências vividas no país de origem (Baggio, 2016). Percebe-se a recriação de espaços para a vivência da fé em Cuiabá inspirados nas experiências anteriores, fato também observado por Pereira (2016). Muitos haitianos eram de diferentes denominações religiosas anteriormente e agora, em Cuiabá, se encontram agregados no mesmo espaço religioso buscando manter a identidade haitiana dentro da sociedade acolhedora. Annemarie Dupré, ex-diretora do Serviço para Refugiados e Migrantes da Federação Italiana das Igrejas protestantes chama atenção para o papel da religião em uma concreta possibilidade de "membresia transnacional". Dupré (2008) diz ainda que a afiliação religiosa pode ajudar a conservar a identidade originária e a construir ao mesmo tempo uma nova identidade transnacional. Essa nova identidade se encaixa dentro de um processo de decomposição e recomposição Hervieu-Léger (2008). Todavia, o processo de decomposição não nos parece um processo voluntário como assinala HervieuLéger, de dilatação da memória. Esse processo é decorrente de uma situação nova (migração), mas que através da religião ocorre uma recomposição coletiva e voluntária de resgate da memória e identidade haitiana.

Malinowsky (1978) afirma que a reprodução dos costumes nativos é importante para manter a tradição e a moral aprendida com os antepassados. No cenário das vivências religiosas haitianas, onde destacamse as comemorações de datas especiais e festivas, como o Natal e a Páscoa (comuns à religião cristã) foram feitas introduções de celebrações ao Dia da Bandeira do Haiti e o Dia do Imigrante. Esses momentos são festejados com alegria junto a amigos, parentes e até mesmo à comunidade brasileira em eventos especiais, com refeições e músicas típicas do país de origem. Esse convívio com outros de sua terra natal com ênfase nos símbolos e elementos culturais do Haiti demonstram que a religião é esfera dedicada ao sagrado, mas também figura como circuito identitário, onde se interligam aspectos espirituais, sociais, culturais que contribuem para manter a identidade 
dessa coletividade. Essa observação também foi feita por Jorn Borup e Lars Ahlin em um artigo publicado no Nordic Journal of Migration Research, como resultado de estudos sobre migrantes católicos vietnamitas na Dinamarca. Eles chegaram à conclusão de que no caso específico da religião não tinha sido um elemento promotor de aculturação. Entretanto, reconheciam que a afiliação religiosa foi instrumental para que o grupo minoritário mantivesse sua identidade (Borup \& Ahlin apud Baggio, 2016).

A despeito das diferenças entre denominações batista nacional e presbiteriana haitianas, elas são instituições que buscaram manter uma identidade cultural e doutrinária, sem negar a autonomia local e é justamente neste equilíbrio que os imigrantes haitianos forjaram as comunidades étnicas denominacionais.

Alvarenga (2017 p. 25) destaca a tese da socióloga francesa Danièle Hervieu-Léger, inspirada nos estudos memorialistas de Maurice Halbwachs que "Toda religião implica numa mobilização específica da memória coletiva", e apresenta a discussão de vários autores abordando a sua aplicação aos cultos afro-brasileiros. Ainda que o presente estudo não tenha a pretensão de apresentar uma identidade para a religião haitiana, a vivência religiosa dos mesmos, sejam os batistas ou os presbiterianos, pode sim ser comparada ao resgate da "memória coletiva", pois, a intenção daqueles que antes eram religiosos de viver uma continuidade religiosa. Logo, a busca pela denominação é intencional e tem o caráter de legitimar sua identidade religiosa de tradição familiar. A conformidade das comunidades étnicas é legitimadora desta intencionalidade que pode ser vista como tentativa de resistência cultural através da religiosidade, ainda que conformando movimentos de "guetos" e "dinâmicas sectárias" (Da Silva 2015, p.98-99). A autora questiona se esses grupos contribuem para a incorporação sociocultural ou geram desagregação social. Suas indagações abordam vários aspectos também questionados por este trabalho, porque se visto por certo prisma as comunidades étnicas provocam sim em alguns imigrantes a sensação de se instalarem como verdadeiros guetos nas comunidades religiosas brasileiras, devido principalmente pela autonomia dos grupos que possuem grande coesão interna. Contudo, a sociabilização desses grupos com as comunidades locais contradiz pensamentos separatistas, ao contrário, as comunidades brasileiras acolhem a tal ponto de incentivar a manutenção das tradições culturais dos imigrantes, não por preconceito, mas pôr entenderem a importância da preservação das crenças de origem. "Haitianos e haitianas se protegem!" 
"Haitianos são tudo irmão!" Esse último termo era mencionado por indivíduos não religiosos também fortalecendo a familiaridade em terras estrangeiras.

Estar junto dos seus conterrâneos era relatado como atitude importante e lhes fazia bem à saúde. Marinucci (2017) afirma a dimensão religiosa na jornada dos imigrantes pode ser recurso simbólico para enfrentar diferentes desafios da integração à sociedade estrangeira. Por caracterizar momento propício a situações conflituosas a religião acaba por trazer uma sensação de proteção diante das adversidades e ajuda o migrante a reinterpretar o sentido e a continuidade da vida. Essa "racionalidade religiosa" tem papel fundamental em todos os estágios da imigração, iniciando-se na decisão de migrar e na preparação da viagem, momento no qual a liderança religiosa pode ofertar apoio ou não, aconselhando a renúncia ou o adiamento da viagem, o que significa ser a anuência do sagrado condição obrigatória para a partida (Marinucci 2017). Na chegada à sociedade estrangeira, as comunidades religiosas locais continuam esta função no acolhimento e apoio oferecidos, o que proporciona sentimentos de amparo possíveis graças às situações na qual revivem as relações primárias dos seus antigos cotidianos, vividas no contexto familiar, espiritual, social e material.

\subsection{Religião como rede de apoio social}

A religião entre haitianos está implicada também no processo saúdedoença/sofrimento. Os sofrimentos relacionados à migração são estímulos para a busca e permanência nas instituições religiosas, porque nesse espaço as pessoas podem contar com suporte de um grupo estruturado em momentos de necessidade, o que pode resultar em melhorias na saúde (Valla 2011).

O apoio social é conceito amplamente utilizado na literatura em saúde (Faria e Seidl 2005; Guimarães et al. 2009; Trad 2003; Valla 1999), como sendo qualquer tipo de suporte emocional, material ou mesmo informacional obtido por meio das relações do seu círculo de amizade, desde as mais íntimas como de familiares ou amigos até as mais distantes formadas por grupos comunitários ou instituições. São ações simples caracterizadas por processos recíprocos de bem-estar benéficos tanto para quem o recebe quanto a quem o oferece. Essas relações possibilitam melhor controle sobre suas vidas, ajustando o sentido do viver e das escolhas sobre os seus destinos (Valla 1997) tendo um papel importante na manutenção da saúde e prevenção de doenças. A religião é um caminho alternativo para a resolutividade de problemas de saúde entre as classes populares (Valla 1997; 2000; 2001). 
Em nossa pesquisa verificamos muitas situações de vulnerabilidade, problemas de saúde mental e necessidades da população haitiana em CuiabáMT. Eles sofrem por estar longe das famílias e amigos, para as quais enviam auxílio financeiro. Geralmente, moram vários haitianos em uma mesma casa, quase sempre extremamente pequena e com pouca mobília, sem camas e maior privacidade. Estranham a comida e têm dificuldade para se comunicar e enfrentam barreiras para conseguir e permanecer no emprego. A essas condições de vida inadequadas somam-se situações de ilegalidade (falta de documentação), desemprego, precariedade nas condições de trabalho, baixos salários, atraso de salário e patrões autoritários. Muitas situações de discriminação e violência foram relatadas. "Tinham que se cuidar porque a violência está para todo o lado". A situação mais citada foi a perseguição por parte de colegas de trabalho brasileiros. Após humilhações sucessivas alguns foram demitidos ou se demitiram, porque geravam muito sofrimento dados os insultos e calúnias, também reportado por Leão et al. (2017) em termos de intimidação, humilhação e desrespeito. A interação social de indivíduos vitimados pelo preconceito racial e/ou social é, com certeza, prejudicada; o comportamento dessas pessoas tende a ser retraído e pouco interativo, mesmo as relações já estabelecidas tendem a se tornar menos confiantes e profundas, fazendo que muitos se sociabilizem apenas entre o seu grupo étnico. "Era porque essas pessoas não gostam de pretos, porque diziam que haitiano é sujo e fedido”, o que demonstra a existência de iniquidades no ambiente laboral e nos espaços sociais na sociedade acolhedora de imigrantes pobres.

Surpreende a quantidade de imigrantes bem qualificados (médicos, enfermeiros, técnicos de enfermagem, administradores, professores etc.) exercendo funções fora da sua área profissional e recebendo salários bem abaixo do esperado, devido à falta de revalidação de diplomas e reconhecimento profissional.

Outra questão bem presente é o trabalho informal como alternativa de sobrevivência, o que De Sá (2016) também verificou acontecer com grupos de imigrantes haitianos em Belo Horizonte.

A maioria dos entrevistados disse gozar de boa saúde. Alguns relataram sofrer de hipertensão e dores de cabeça, no corpo e insônia. Vários tipos de manifestações de sofrimento físico e psicossocial e outros sintomas categorizados por Victor Valla como sofrimento difuso foram observados em campo: dores na coluna, dor de cabeça, na barriga ou corpo inteiro, 
cansaço, insegurança, dificuldade para dormir, contudo, o mais frequente era a saudade da família e do lar.

A religião como rede de suporte social, emocional e afetivo que interfere em aspectos biopsicossociais importantes para a saúde foi evidenciada nessa investigação. No campo, apareceram alguns relatos importantes que ressaltam problemas na saúde mental e também o apoio social oferecido.

Em várias entrevistas, haitianos relataram ter procurado ajuda médica pelo menos uma vez, para tratar algum sintoma equivalente ao sofrimento difuso; e, pelo mesmo motivo, ter procurado a ajuda pastoral para aconselhamentos, orientações em momentos de indecisões e inseguranças e também, ter buscado na comunidade religiosa, orações e conforto, em momentos de tristeza e solidão.

No período de doze meses em campo, muitas histórias inspiradoras e dramáticas se revelaram, entretanto, uma em especial chamou atenção: o sofrimento experimentado por Samuel, que resume quadros semelhantes vivenciados por outros imigrantes. Esse era um jovem com frequência assídua aos encontros religiosos sempre marcado por uma elegância ao vestir: fato também demonstrado por Araújo (2015), que mostra ao grupo que seu projeto migratório é bem-sucedido.

Samuel auxiliava diversas tarefas na comunidade batista. No cotidiano, atuava como garçom em uma pizzaria durante a semana e fazia "bicos" em festas para trazer sua namorada para o Brasil. Economizou ao máximo para isso durante quatro anos. Casou-se com ela com o apoio da comunidade religiosa. Passados quatro meses do casamento, começou a se comportar de forma diferente, chamando a atenção da esposa que pediu ajuda para amigos que recorreram ao pastor da igreja. Os sintomas iniciais foram agitação, nervosismo, insônia e falta de apetite, depois se seguiram episódios de confusão mental, até que, no terceiro dia ele se despiu e saiu correndo de casa. Chamaram novamente o pastor, que passou a noite orando com um grande grupo em sua casa. Essa prática de visitas domiciliares por líderes religiosos é caracteriza por Guimarães et al (2009 p. 3) como "atos terapêuticos" cuja disponibilidade para a escuta permite a devida atenção ao indivíduo e sua família.

O seu sofrimento perdurou por dois dias, com pouca clareza ao falar, lentidão na compreensão e dificuldade de percepção sensorial, desorientação espaço-temporal e alucinações, confusão mental, choros e risos. Citava 
versículos bíblicos sem parar e pedia ajuda para orar. Foi diagnosticado e medicado com estresse pós-traumático, passados 12 dias recebeu alta da Unidade de Saúde, após melhora do quadro, sem nenhuma orientação ou encaminhamento para especialista.

A rede de mulheres da igreja batista prestou todo apoio social. O grupo tomou conhecimento sobre a Síndrome do Imigrante, confirmando que Samuel apresentava há tempos sintomas similares desse clínico clássico descrito por Franken, Coutinho e Ramos (2012) tais como a insônia, nervosismo, lapsos de memória, momentos de isolamento que progrediram para agressividade e surto psicótico. Knoblock (2015) relata a existência da Síndrome do Migrante, que não é uma doença mental, mas apenas um quadro reativo às mudanças em sua vida que necessita de prevenção por meio de abordagem psicossocial e contenção emocional, negando a necessidade de medicalização.

Durante o episódio o pastor relata que a família desejava que fosse formada uma equipe de oração 24 horas por ele: "Algo como exorcizar o espirito ruim até sair dele". Ele dizia que "alguns deles (os imigrantes haitianos) pensam que doenças podem ser causadas por espíritos malignos". A associação entre sofrimento mental e problema espiritual é comum. A respeito da "doença espiritual" Guimarães et al (2009 p. 5) relacionam à noção de desordem em que a enfermidade afeta "o corpo físico, social e espiritual", de modo que, o "vigor moral, a vontade pessoal e o fluxo de energia do cotidiano" são alterados também, podendo debilitar as funções vitais.

Após esse momento, Samuel afirmara que serviu para mostrar "Quantos amigos têm" e seu conforto foi saber que sua esposa nunca ficou desamparada. Essa situação vivida por este imigrante demonstra que seus sofrimentos se assemelham ao discurso de Valla (1999), que descreveu sobre as queixas não valorizadas pelos serviços de saúde pública. Ele foi diagnosticado e medicado como uma crise emocional, mas o foco não estava no seu sofrimento difuso que pode aumentar caso seu nível de estresse cresça.

Nesse sentido, alertam Guimarães, Valla e Lacerda (2009) a despeito da medicalização do sofrimento difuso com "benzodiazepinicos" para apenas acalmar os sintomas. Isso cronifica a situação do indivíduo que sofre, pois a centralidade é dada à doença e não ao sujeito que deveria ser acolhido integralmente (o que implica na escuta de sua história de vida e o respeito pelo seu sofrimento). Pussetti (2009) descreve a black depression e discute a temática das biopolíticas da depressão em imigrantes, em termos foucaultianos 
das relações de poder referentes às condições de vida desses imigrantes no país de acolhida.

No caso aqui observado, as instituições religiosas que socorreram o haitiano buscaram proteger sua integridade e de sua família, trouxeram conforto para sua esposa, auxiliaram a família na tomada de decisão, providenciaram a medicação e materiais solicitados pelo serviço de saúde, e ainda garantiram que não estivesse sozinho durante o período de internação, e principalmente, compreenderam a situação vivida não discriminando, mas incentivando a mudança do modo de vida.

Aliás, vários foram os casos de intervenções nas comunidades religiosas em relação à compra de medicamentos caros, realização de consultas ou exames ou o socorro às mães grávidas com providência de enxoval, berços, carrinhos de bebê ou fórmula materna específica. Isso se dava de modo organizado por departamentos da igreja ou por ações voluntárias. Essas ações trazem benefícios para a saúde de quem recebe o que necessita e de quem doa (Valla 2000).

Esses fatos vão ao encontro da Teoria do Apoio Social, descrita por Valla (1997) que realça o papel desempenhado pelos indivíduos e suas relações comunitárias na resolução da situação em crise. Observamos trocas que envolveram o apoio emocional e resultou em sentimentos de pertencimento e confiança, frente às angústias, ansiedades, tristezas, medos trabalhados em coletividade para a superação e controle. Em segundo lugar, o apoio material prestado financeiramente por muitas pessoas e de serviços, como o caso do pastor que doou sua gasolina em várias idas até o local de internação. Em terceiro lugar, pelo apoio educacional ou informacional. Houve grande aprendizado que gerou uma nova visão sobre as vivências durante a migração e, também, sobre a atuação da instituição religiosa nas vidas dos imigrantes - que tiveram a oportunidade de ver quão importante é seu papel para a vida deles.

Nessas práticas de ajuda destaca-se o papel da liderança. O pastor haitiano tem a convicção de que seu papel é divinamente inspirado: "Deus trouxe eu pra cá; Ele enviou o missionário; Ele cuida de mim, cuidou no Haiti, cuidou na viagem e cuida até agora de todo mundo, Ele ama os haitianos". Ele trabalhava como professor do ensino fundamental até se formar no seminário presbiteriano no Haiti. O conselho religioso de sua igreja decidiu enviá-lo para o Brasil. Sua missão era apoiar "seus irmãos". 
Falam os pastores que o seu trabalho é oferecer apoio espiritual e social em todas as áreas necessárias, qualquer tipo de ajuda solicitada, aconselhamento pessoal e conjugal, e principalmente o ensino bíblico. Dizem ainda, acompanhar quem tem dificuldade em falar português para fazer documentação ou entrevista de emprego, nas questões de saúde, orientam, encaminham e transportam quem precisa ir ao hospital, os dois relatam que os seus veículos particulares sempre estão disponíveis.

E sobre o que ele faz para ajudar, responde que aconselha, prega segundo a palavra: "Tudo vai acabar um dia, o sofrimento vai acabar um dia, desempregados, tudo vai acabar um dia”. Que incentiva 'além da esperança em Deus' a amizade e procura estar próximo deles, ao fazer visita convida alguém para estar junto, tentando envolver o máximo de imigrantes no trabalho social da comunidade.

Sobre o impacto do seu trabalho um dos líderes afirma claramente seu papel no apoio social: "É forte, tem investido na evangelização e apoio... apoio social é durante visitação em uma casa, e a pessoa tá passando necessidade, tá doente, a gente primeiro ora, acompanha e providência o que puder”. Em síntese, a atividade pastoral também envolve práticas de cuidado integral em saúde entre os haitianos.

\section{$2.5 \mathrm{O}$ silenciamento do Vodu no protestantismo}

Considerando o vodu como tradição religiosa reconhecida internacionalmente como fator de resistência étnica haitiana (Baptista 2012; Carrasco 2015; Evangelista 2010; Handerson 2017; Nicolas et al 2007; Padilla 2013) chamou atenção a ausência de relatos de experiências, além das cristãs entre essa população, apesar de estudos demonstrarem sua prática no Brasil.

$\mathrm{O}$ vodu não aparecia nas entrevistas ou observações. Isso indicou seu silenciamento entre haitianos inseridos em comunidades protestantes em solo brasileiro - ainda que constituída apenas de haitianos. Após um período, egos focais da pesquisa disseram haver "um grupo barra pesada no bairro Pedregal" que era praticante de tal religião antes de sair do Haiti e não a tinham abandonado. Demonstrou-se nítido receio (até mesmo certo preconceito) ao dizer a respeito: "Deles ninguém se aproximava se eles não quisessem”. Houve tentativas de investigá-los, mas sem sucesso. Aqui se evoca o esquecimento social, a amnésia social, causada no âmbito das lutas dos grupos e classes distintas (POLLACK, 1989). Existem nas lembranças de uns e de outros, zonas de sombras, silêncios e "não ditos": 
As fronteiras desses silêncios e "não-ditos" com o esquecimento definitivo e o reprimido inconsciente não são evidentemente estanques e estão em perpétuo deslocamento. Essa tipologia de discursos, de silêncios, e também de alusões e metáforas, é moldada pela angústia de não encontrar uma escuta, de ser punido por aquilo que se diz, ou, ao menos, de se expor a mal-entendidos (POLLAK, 1989, p.8).

Dentro das comunidades religiosas muitos respondiam sobre os que praticam o vodu: "Haitiano que não frequenta igreja e não sai de bares, é do vodu. E que desses, eles (os haitianos evangélicos ou protestantes) não procuram amizade". Um importante contato da pesquisa de campo, por exemplo, apenas depois de meses relatou que seu irmão era sacerdote voduísta. Justificou-se dizendo que ele como auxiliar de uma igreja protestante brasileira se sentia em uma posição desconfortável por ter um parente em tal posição, "mas no Haiti isso é comum". Falou que nós brasileiros entendemos o vodu apenas como uma religião, mas para o haitiano mesmo que não a pratique como tal, faz parte de sua cultura, nas práticas do dia-a-dia ensinadas por gerações. Alguns disseram não saber quase nada sobre essa religião, além do que é ensinado na escola sobre a sua história e outros negaram haver relação dessa com a religião cristã. Nesse sentido, Pollak diz que há uma fronteira "entre o dizível e o indizível, o confessável e o inconfessável” que separa "uma memória coletiva subterrânea da sociedade civil dominada ou de grupos específicos, de uma memória coletiva organizada que resume a imagem que uma sociedade majoritária ou o Estado desejam passar e impor" (Pollak, 1989, p.8).

Isso também demonstra a nuance do olhar etnocêntrico herdada da religião colonizadora que gera receios de rejeição pela hegemonia da religião cristã no Brasil. Com o tempo de campo, foi ficando claro que "No Haiti pratica o vodu quem quer, pode ser religioso ou não". Um entrevistado enfatizou que o vodu é uma das religiões mais fortes no Haiti e foi importante para sua História, ganhando espaço dentro da nação, mas que "Vodu só lá, aqui não".

\section{Considerações finais}

Essa pesquisa mostrou que na dinâmica de inserção de imigrantes haitianos na sociedade acolhedora a religião tem se destacado. As instituições evangélico/protestantes, aqui analisadas, demonstram que a religião atua como um recurso simbólico favorecendo sentimentos de pertencimento/ socialização, contribuem na manutenção da identidade dos imigrantes e se configura como uma importante rede de suporte social com reflexos na saúde 
desse grupo social. O silenciamento de algumas formas de religião mais características, especialmente o vodu, no âmbito do protestantismo merece aprofundamentos no sentido de perceber os impactos desse ocultamento para esse grupo social.

O ambiente da comunhão, os ritos, a musicalidade, as preces, assim como a demanda pelo apoio social pouco se diferenciavam e incentivam à continuidade da sua fé e prosseguimento da vida.

A religião como recurso da memória coletiva, mobiliza um sistema de crenças e produz sociabilidades que diminuem o isolamento social e a solidão. Também se caracteriza como auxílio para superarem a realidade estressante vivida geradora de sofrimento por conta dos impasses do cotidiano. Ela ajuda no alívio temporário ou permanente da dor física e mental e contribui para tornar a vida cotidiana mais tolerável e significativa propiciando melhor saúde física e mental.

\section{Referencias}

ALVARENGA, Leonardo. Os batistas em movimento: um estudo da dinâmica sócio religiosa de batistas no Brasil: o exemplo de Macaé-RJ. São Paulo, 2017. 260 p. Tese de Doutorado (Doutorado em Ciência da Religião) - Programa de Pós-Graduação em Ciência da Religião, PUC-SP.

ANGROSINO, Michael. Etnogragia e observação participante. São Paulo, Artmed, 2009.

ARAÚJO, Adriano A. Reve de Brezil: a inserção de um grupo de imigrantes haitianos em Santo André. Santo André, 2015. 172 p. Dissertação de Mestrado. Universidade Federal do $\mathrm{ABC}$.

BAGGIO, F. Las religiones de los inmigrantes: una visión general. In: BAGGIO, Fabio; PARISE, Paolo; SANCHEZ, Wagner Lopes. Mobilidade humana e Identidades religiosas. - São Paulo: Paulus, 2016.

BAPTISTA, José R. Sè Tou Melanje: Uma etnografia sobre o universo social do Vodu Haitiano. Rio de Janeiro, 2012. 326 p. Tese de Doutorado. UFRJ: PPG em Antropologia Social.

BARTEL, Carlos E. Integração social dos imigrantes haitianos no interior do Brasil: o caso de Presidente Getúlio/SC”. III Encontro Estadual de História da ANPUH, RS. Santa Cruz do Sul, 18 jul. 2016. Disponível em: http://www.eeh2016.anpuh-rs.org.br/resources/ anais/46/1468615073_ARQUIVO_IntegracaosocialdoshaitianosemPresidenteGetulio.pdf. Acesso em 01 nov. 2018.

BERGER, Peter L. O dossel sagrado: elementos para uma sociologia da religião. São Paulo: Paulus, 1985. 
BOAS, Franz. Antropologia Cultural. Rio de Janeiro: Jorge Zahar Editor, 2004.

DA SILVA, Anaxsuell F. Práticas religiosas em contexto migratório: o caso da tríplice fronteira latino-americana. Inter-Legere, Natal-RN, (17): p. 89-104, ago/dez, 2015.

DA SILVA, Sidney. Brazil, a new Eldorado for Immigrants? The Case of Haitians and the Brazilian Immigration Policy. Urbanities, Italy, 3(2): p. 3-18, 2013.

DE SÁ, Patrícia R. As redes sociais de haitianos em Belo Horizonte: análise dos laços relacionais no encaminhamento e ascensão dos migrantes no mercado de trabalho. Cadernos OBMigra, Brasília. Cadernos; 1(3)99-127, 2015.

DUARTE, Rosália. Pesquisa qualitativa: reflexões sobre o trabalho de campo. Cadernos de Pesquisa, São Paulo. 115: p. 139-154, março, 2002.

DUPRÉ, A. What Role Does Religion Play in the Migration Process? Mozaik, Trento, Italy (1), p. 7-11, 2008.

ELIADE, M. O sagrado e o profano: a essência das religiões. São Paulo: Martins Fontes, 2001.

EVANGELISTA, Felipe A.S. Construções do fracasso haitiano. Rio de Janeiro, 2010. 173 p. Dissertação de Mestrado. UFRJ, PPG em Antropologia Social/Museu Nacional.

FARIA, Juliana B. SEIDL, Eliane M.F. Religiosidade e enfrentamento em contextos de saúde e doença: revisão da literatura. Psicologia: Reflexão e Crítica, Porto Alegre. Vol.18, n.3, p.381-389, 2005.

FRANKEN, Ieda et al. Representações sociais, saúde mental e imigração internacional. Psicologia: Ciência e Profissão, Brasília. 32 (1) 202-219, 2012.

FREITAS, Marta H. Relações entre religiosidade e saúde mental em imigrantes: implicações para a prática psi. Psico-USF, Bragança Paulista. 18(3): p. 437-444, set/dez, 2013.

GEERTZ, Clifford. A interpretação das culturas. Rio de Janeiro: Guanabara, 1989.

GUIMARÃES, Maria B. et al. As redes de apoio social constituídas por pastores e agentes comunitários de saúde evangélicos no âmbito do cuidado e atenção à saúde da população.

Koinonia - Religião e Saúde, Rio de Janeiro. 4 (16): p. 1-7, julho, 2009.

HANDERSON, Joseph. (2017), A historicidade da (e)migração internacional Haitiana.

O Brasil como novo espaço migratório. In: FELDMAN-BIANCO, B e CAVALCANTI, L. (orgs). Dossiê: Imigração Haitiana no Brasil - estado das artes. Periplos, Revista de Investigación sobre migraciones, Brasília. v. 1 n. 1, p. 7-26, 2017.

HERVIEU-LÉGER, Danièle. O peregrino e o convertido: a religião em movimento. Petrópolis, RJ: Vozes, 2008

JOSEPH, Jean. Missão e Igreja local: um estudo do vodu haitiano no contexto do pluralismo religioso. São Paulo, 2014. 115 p. Dissertação (Mestrado). PUC-SP: Faculdade de Teologia Nossa Senhora da Assunção.

KNOBLOCH, Felícia. Impasses no atendimento e assistência o migrante e refugiado na saúde e saúde mental. Psicologia USP, São Paulo. 26(2): p. 169-174, 2015. 
LEÃO, Luís H. C, et al. Migração internacional, saúde e trabalho: uma análise sobre os haitianos em Mato Grosso, Brasil. Cadernos de Saúde Pública, Rio de Janeiro. 33(7):e00181816, 2017.

LIMA, C.M.P.; VALLA, V.V. Religiosidade popular e saúde: Fome de que? In: Anais Encontro Nacional de Pesquisa em Educação em Ciências, Bauru, 2005. s/p.

MALINOWSKI, Bronislaw. Argonautas do Pacífico Ocidental. São Paulo: Abril Cultural, 1978.

MARCUS, George E. Ethnography in/of the World System: The Emergence of Multi-Sited Ethnography. Annual Review Anthropology, Palo Alto, Califórnia. (24): p. 95-117, 1995.

MARINUCCI, Roberto. A Religiosidade do Migrante como Fonte de Proteção, Sentido, Dignidade e Diálogo. Caderno de debates 8, Brasília. 8(8), p.73-89, 2013.

MARINUCCI, Roberto. O compromisso das religiões junto aos migrantes. CSEM, Resenha Migrações na atualidade, Brasília. 28 (108):setembro. s/p, 2017.

NICOLAS, Guerda et al. Expression and Treatment of Depression among Haitian Immigrant Women in the United States: Clinical Notes. American Journal Of Psychotherapy, Washington. 61(1): p. 82-98, 2007.

PADILLA, Beatriz. Saúde dos imigrantes: multidimensionalidade, desigualdades e acessibilidade em Portugal. REMHU, Revista Interdisciplinar da Mobilidade Humana, Brasília, 21(40): p.49-68, 2013.

PEREIRA, Rosa. (2016), Bondye beni ou: lugaridades com haitianos evangélicos. Curitiba, 2016. 300 p. Tese (Doutorado em Geografia) - Universidade Federal do Paraná: PPG em Geografia.

POLLAK, Michael. Memória, Esquecimento, Silêncio. Estudos Históricos. Rio de Janeiro, Vol. 2. n. 3, 1989, p. 3-15.

PUSSETTI, Chiara. Biopolíticas da Depressão nos Imigrantes Africanos. Saúde e Sociedade, São Paulo, 18(4): p. 590-608, 2009.

SILVA, Alcione L. Pesquisa-ação participante no processo de empowerment de mulheres brasileiras no contexto da migração internacional. Revista de Enfermagem Escola Anna Nery, Rio de Janeiro. 12(4): p. 750-757, dez, 2008.

TRAD, Leny A. B. Processo migratório e Saúde Mental: rupturas e continuidade na vida cotidiana. PHYSIS: Rev. Saúde Coletiva, Rio de Janeiro, 13(1): p. 139-156, 2003.

SANTOS, Fabiane V. A inclusão dos migrantes internacionais nas políticas do sistema de saúde brasileiro: o caso dos haitianos no Amazonas. História, Ciências, Saúde, Rio de Janeiro. 23(2):477-494, abr-jun, 2016.

VALLA, Victor. Educação popular, saúde comunitária e apoio social numa conjuntura de globalização. Cadernos de Saúde Pública, Rio de Janeiro, 15(Sup.2): p. 7-14, 1999.

VALLA, Victor. Globalização e saúde no Brasil: a busca da sobrevivência pelas classes populares via questão religiosa. In: VASCONCELOS, Eymar. Educação popular nos serviços de saúde. 3. ed. São Paulo: HUCITEC, 1997. 
Significados das práticas religiosas para a saúde de imigrantes haitianos em Cuiabá-MT. 215

VALLA, Victor. Redes sociais, poder e saúde à luz das classes populares numa conjuntura de crise. Interface Comunicação, Saúde, Educação, Botucatu. 4 (7) : p. 37-56, 2000.

VALLA, Victor. O que a saúde tem a ver com a religião. In: VALLA, Victor (org.) Religião e cultura popular. Rio de Janeiro: DP\&A; p. 113-139, 2001.

VALLA, Victor. Pobreza, emoção e saúde: uma discussão sobre pentecostalismo e saúde no Brasil. Revista Brasileira de Educação, Rio de Janeiro. (19): p. 66-75, 2002.

ZUNIGA CARRASCO, Iván Renato. Vudú: una visión integral de la espiritualidad haitiana. Memorias, Barranquilla. n. 26, p. 152-176, May, 2015.

Submetido em: 2-4-2020

Aceito em: 1-6-2021 